\title{
Fatores de Risco ao Envolvimento de Mães com Filhos Pré-Escolares: Associações com Estresse e Burnout
}

\author{
Tatiane Oliveira Zanfelici \\ Centro Universitário Hermínio Ometto \\ Araras, SP, Brasil \\ Elizabeth Joan Barham \\ Universidade Federal de São Carlos \\ São Carlos, SP, Brasil
}

\begin{abstract}
RESUMO
O trabalho dos pais pode relacionar-se positiva ou negativamente ao desenvolvimento dos filhos, a depender da frequência com a qual demandas domésticas e profissionais interferem no envolvimento parental. O objetivo deste estudo foi examinar as relações entre demandas de trabalho, estresse, burnout e envolvimento parental em 56 trabalhadoras com filhos de 3 a 5 anos. Aferiram-se os sintomas de estresse e burnout e o envolvimento com o filho utilizando escalas testadas em outros estudos. Verificou-se que as mulheres que afirmavam dedicar mais horas a tarefas domésticas atingiram escores de estresse e burnout mais altos e relataram menor frequência de envolvimento com seu filho. Os resultados elucidam uma fase crítica na vida de trabalhadoras com filhos pequenos, apontando a necessidade de fortalecer a rede de suporte para estes indivíduos, bem como desenvolver políticas públicas, para reduzir a sobrecarga e o estresse parental.
\end{abstract}

Palavras-chave: Dupla Carreira; Stress; Relações Familiares; Trabalho da Mulher.

\section{ABSTRACT}

\section{Risk Factors for the Involvement of Mothers with Preschool Children: Associations with Stress and Burnout}

Parents' work can have a positive or negative influence on their children's development, depending on the frequency with which housework and job demands interfere with their parenting involvements. The goal of this study was to examine the relationships that exist among work demands, stress, burnout and parental involvement among 56 mothers of children between 3 and 5 years of age. Stress, burnout and involvement with a target child were evaluated using instruments tested in previous studies. Mothers who reported spending a greater number of hours on domestic chores reported higher stress and burnout scores and lower frequency of involvement with their child. These results shed light on a critical phase in the life of working women, when their children are young, pointing to a need to strengthen the support network for these workers, and to develop public policies in order to reduce the stress and burden felt by working parents.

Keywords: Double Career; Stress; Family Relations; Working Women.

\section{RESUMEN}

Factores de Riesgo a la Participación de las Madres con los Niños de Preescolar: Asociaciones con Estrés y Agotamiento El trabajo de los padres puede relacionarse positivamente o negativamente al desarrollo de los niños, dependiendo de la frecuencia con la que las exigencias domésticas e profesionales interfieren con participación parental. El objetivo del estudio fue examinar la relación entre las exigencias del trabajo, el estrés, burnout y la participación en 56 trabajadores con niños 3 o 5 años. Han evaluado son los síntomas de estrés y burnout y el la participación con el niño utilizando escalas probadas en otros estudios. Se observó que las mujeres que afirmaban que dedicar más horas a las tareas domésticas alcanzaron puntuaciones más altas en el estrés y el burnout y evaluados como menos involucrados con sus hijos. Los resultados aclaran una fase crítica en la vida de trabajar con los niños pequeños, que apunta a la necesidad de ampliar la red de apoyo para estas personas, así como la desarrollo de las políticas públicas para reducir la sobrecarga y el estrés de los padres.

Palabras clave: Doble Carrera; Estres; Relaciones Familiares; Trabajo de Mujeres. 
A família compõe um microssistema central na vida das crianças e representa uma das mais importantes influências sobre o desenvolvimento humano nesta fase da vida (Pedroso \& Motta, 2010). A partir dessa premissa, fundamentada pela abordagem bioecológica de Bronfenbrenner (1979/1996), pesquisadores visam compreender fatores que afetam a qualidade das relações entre crianças e adultos, levando em conta as habilidades e necessidades dos mesmos, as quais variam ao longo do tempo e de acordo com o contexto em que a família está inserida. Ainda, a abordagem bioecológica destaca o potencial das influências extrafamiliares, tais como a vizinhança da família, as redes sociais dos pais e os efeitos das condições físicas e interpessoais do trabalho, como elementos que interagem com os familiares para fortalecer ou reduzir o envolvimento parental.

Segundo Bronfenbrenner (1979/1996), consideram-se partes deste exossistema os ambientes que influenciam o desenvolvimento da criança, mesmo que esta não participe dos mesmos diretamente. Como os adultos envidam diversos esforços às necessidades profissionais e às de educação e cuidados de seus filhos, o trabalho dos pais afeta as condições psicológicas e materiais da família e pode afetar o desenvolvimento infantil. As necessidades das crianças também trazem influências sobre o desenvolvimento de seus pais, à medida que afetam planos, prioridades, rotinas e estados de humor.

Pesquisadores (Simões, Farate, \& Pocinho, 2011; Ferreira \& Barreira, 2010; Cia \& Barham, 2009) apontam que pais que apresentam maior envolvimento, disposição e qualidade de interações com seus filhos parecem influenciar o desenvolvimento dos mesmos positivamente. Comportamentos parentais como estimulação física e verbal, sensibilidade e disponibilidade às necessidades da criança e encorajamento da autonomia da mesma, além da presença de recursos físicos, podem contribuir significativamente para o desenvolvimento infantil (Mondin, 2008). Os autores enfatizam também a importância de manter hábitos como ler para as crianças, tecer comentários sobre o mundo que as cerca, ter disposição para perguntar e responder, além de utilizar palavras que sejam acessíveis ao estágio de desenvolvimento em que a criança se encontra. Este contato pode ser enriquecido com brinquedos e livros de histórias, sendo que a presença dos pais potencializa o poder de estimulação destes recursos.

Por outro lado, a ausência, empobrecimento ou inadequação do contato e estimulação entre pais e criança estão ligadas a diversos problemas de desenvolvimento (Simões, Farate, \& Pocinho,
2011). Muitas práticas parentais relacionadas à dificuldade em enfrentar emoções negativas podem contribuir com o aumento de probabilidade de maus tratos e negligência à criança (Mondin, 2008). As situações de estresse crônico refletem a incapacidade ou impossibilidade de desenvolver estratégias para lidar adequadamente com o conjunto de demandas enfrentadas. Esta condição colabora para o surgimento de interações negativas entre pais e seus filhos, constituindo um dos fatores que influenciam no aumento da irritabilidade dos pais e contribuindo para a emergência ou manutenção de trocas aversivas com as crianças, além de facilitar o surgimento de reações destrutivas, perante comportamentos agressivos manifestados por elas (Mondin, 2008; Kazdin \& Whitley, 2003). O enfrentamento inefetivo do estresse, além de desgastar relações com os filhos, colaboraria para o surgimento de problemas de comportamento nas crianças, as quais se tornarão estressores adicionais.

Dessa forma, é gerado um círculo vicioso de trocas negativas que afetam pais e crianças mutuamente. Pais centrados em seus problemas podem gerar relações parentais menos eficientes e de pior qualidade (mais aspereza, menos envolvimento, mais práticas negativas e disciplina ineficaz) (Simões, Farate, \& Pocinho, 2011; Nunes-Costa, Lamela, \& Figueiredo, 2009). Dificuldades para lidar com as demandas contínuas de cuidar de filhos pequenos podem exacerbar desacordos sobre a divisão das tarefas domésticas e dos cuidados com as crianças, ocorrendo com frequência nos primeiros anos de vida dos filhos, caracterizando uma etapa do ciclo da vida familiar mais suscetível ao divórcio (Dessen \& Braz, 2005). Além disso, transmitem-se aos filhos modelos de enfrentamento inadequados (Pinquart \& Silbereisen, 2005).

Ambientes familiares inadequados ou privados de suporte familiar, onde crianças pouco se relacionem com os pais e as condições básicas para seu desenvolvimento são inapropriadas ou inexistentes, podem configurar situações de risco para o desenvolvimento infantil (Patias, Siqueira, \& Dias, 2013). De acordo com Eisenstein e Souza (1993), um fator de risco pode ser descrito como um elemento causador ou modulador de eventos indesejáveis, isto é, um intensificador de vulnerabilidade. Com base no modelo teórico de Bronfenbrenner, podese acrescentar que os prejuízos no desenvolvimento são produzidos por um conjunto de riscos genéticos, biológicos, psicológicos e ambientais, envolvidos em interações complexas. Dessa forma, o desenvolvimento infantil poderá ser afetado, de maneira negativa ou positiva, de acordo com as condições do ambiente 
em que a criança está inserida. Ou seja, para que o desenvolvimento da criança seja potencializado, é desejável que o ambiente familiar seja saudável não apenas fisicamente, mas também no que diz respeito às relações interpessoais (Patias, Siqueira, \& Dias, 2013).

Segundo Cia, Barham e Fontaine (2012), com base em uma revisão de pesquisas acerca da importância da figura paterna para o desenvolvimento infantil, envolvimentos mais intensos entre pais e filhos contribuem significativamente para o desenvolvimento positivo do autoconceito e do desempenho acadêmico das crianças. Por exemplo, quando se compara envolvimento parental e autoconceito acadêmico em crianças cujos pais trabalhavam em turnos noturno versus diurno, Cia e Barham (2005) encontraram resultados que apontavam diminuído autoconceito acadêmico em filhos de pais que trabalhavam no período noturno. Embora não seja possível estabelecer causalidade em dados correlacionais, as autoras levantaram a hipótese que este fenômeno poderia ocorrer devido ao menor envolvimento destas crianças com seus pais em aspectos como comunicação entre pais e filhos, participação dos pais em ocasiões de lazer, estudo e cultura, e tempo que os pais passavam fazendo atividades com os filhos.

No estudo desenvolvido por Dekovic e Meuis (1997) com pais, mães e seus filhos adolescentes, pesquisadores indicaram que a qualidade do relacionamento pai e filho (avaliada na pesquisa por um composto de medidas de aceitação, simpatia e envolvimento) estava positivamente correlacionada com a qualidade do relacionamento dos adolescentes com seus pares e com o autoconceito geral dos adolescentes. Atualmente, mesmo com o aumento do número de mulheres que conciliam tarefas profissionais com as familiares, parece que o envolvimento paterno não foi significativamente alterado, sendo que os pais frequentemente precisam escolher entre as necessidades familiares e as demandas do trabalho (Cia \& Barham, 2005). Por conseguinte, mesmo mães de filhos dependentes que convivem com o pai de suas crianças lidam com uma carga significativamente maior (mais do que o dobro) de responsabilidades familiares do que seu marido, na grande maioria dos casos (Vanalli, 2012). Assim, nem sempre a vida familiar e os afazeres domésticos recebem a devida atenção, sendo relegada em segundo lugar, sendo preterida às atividades profissionais.

$\mathrm{O}$ fato de pais e mães trabalharem em atividades remuneradas traz diversos ganhos para a família, como a indispensável manutenção e até a melhoria das condições financeiras e materiais, mas pode também desencadear algumas situações desvantajosas na relação e no cuidado com os filhos. De acordo com a atual Pesquisa Nacional por Amostragem de Domicílios (IBGE, 2012), 37,4\% dos domicílios brasileiros são chefiados por mulheres. Todavia, isso parece não isentar as mulheres da dupla jornada. Soares e Sabóia (2007) discutem que desde meados da década de 2000, 92\% das trabalhadoras remuneradas declararam responsabilidade pelo serviço doméstico. Os homens têm aumentado suas participações nas tarefas domésticas, mas ainda fazem menos do que as mulheres. Contudo, de acordo com os autores, 51,4\% dos respondentes de sexo masculino têm se incumbido de tarefas domésticas em suas famílias. Desta forma, dentre as diversas mudanças pelas quais as mulheres têm passado no espaço social e na esfera familiar, a divisão de afazeres domésticos parece não acompanhar o ritmo da modificação do papel feminino, mantendo altos índices de desigualdade entre os gêneros. A redução e terceirização do trabalho doméstico pode reduzir as tensões que os casais modernos enfrentam para conciliar a vida profissional e pessoal, mas no papel parental, todavia, a estratégia de terceirização apresenta limites.

A despeito das evidências de pesquisas que apontam a importância das interações de qualidade entre pais e filhos, ainda não há políticas ou garantias trabalhistas que favoreçam maior participação dos homens na educação das crianças. Mesmo os direitos garantidos a mulheres que trabalham enquanto cuidam de filhos pequenos, com base na Consolidação de Leis Trabalhistas (CLT) e o Estatuto da Criança e do Adolescente (ECA), nem sempre estas provisões se mostram suficientes ou adequadamente cumpridas. Exemplos que ilustram esta afirmativa são o artigo $389 \S 1^{\circ}$ da CLT (Brasil, 2001), que prevê que os estabelecimentos onde trabalham no mínimo trinta mulheres maiores de dezesseis anos de idade devem contar com local apropriado para as funcionárias guardarem sob vigilância e assistência os seus filhos no decorrer da amamentação; e o artigo 9ำ do ECA (1990), que aponta o Poder Público, as instituições e empregadores como responsáveis para propiciar condições apropriadas ao aleitamento materno, porém sem especificar tais condições.

Sabe-se que demandas simultâneas nas esferas pessoal e profissional somadas à sobrecarga de responsabilidades entre trabalho e família podem desencadear conflitos que causam ao indivíduo diversos custos pessoais e profissionais (Goulart Jr., Feijó, Cunha, Correa, \& Gouveia, 2013; Barham \& Vanalli, 2012). O produto desta situação, quando em desequilíbrio e desprovida de suporte social e 
pessoal, é o estresse. Situações de estresse excessivo e prolongado, quando não enfrentadas ou cuidadas adequadamente, podem evoluir para quadros de esgotamento. É neste contexto que surge o burnout, uma cronificação do estresse (Benevides-Pereira, 2010). O burnout inclui três dimensões: exaustão emocional, despersonalização e reduzida realização profissional. Na fase de exaustão emocional, o contato com as pessoas e com o trabalho cotidiano provoca grande desgaste, a ponto de que os acometidos pensem em desistir por não terem mais condições de executarem seu trabalho. A segunda fase, denominada despersonalização, caracteriza-se pela predominância de sentimentos e atitudes negativas, bem como o distanciamento de pessoas e usuários do trabalho. A reduzida realização profissional culmina em uma fase de descontentamento do trabalhador consigo mesmo e com os resultados de seu trabalho (Benevides-Pereira, 2010).

As perturbações físicas, psíquicas e comportamentais sofridas pelos acometidos pelo burnout frequentemente atingem também seus relacionamentos, o que pode dificultar a busca por auxílio. Além disso, os fatores de estresse, sobrecarga e burnout não ocorrem sozinhos no trabalho ou na família, mas podem ser compreendidos como um somatório de diversos fatores sociais interrelacionados (tais como: satisfação com o trabalho de forma geral, bem como com o suporte social, interferências do trabalho na rotina familiar e vice-versa, demandas atuais da vida do indivíduo, a rede de apoio social disponível e oportunidades para a manutenção do próprio lazer e autocuidado). Pais e mães estressados e sobrecarregados, quando não possuem auxílio, prolongam ainda mais tais efeitos neles mesmos, em seus familiares e consequentemente, em seus filhos. Ademais, ao contrário de algumas outros compromissos, os relativos aos filhos e ao próprio trabalho são crônicos e não podem ser constantemente protelados, a menos que se chegue ao extremo de afastar-se totalmente do trabalho (pela demissão) ou da família ( por meio do divórcio) (Zanfelici, 2009).

Diante da hipótese de que interações inadequadas ou insuficientes entre pais e filhos podem constituir riscos para o desenvolvimento infantil, as propostas deste estudo foram: aferir sinais de estresse e esgotamento (burnout) em uma amostra de mães de crianças entre 3 e 5 anos de idade que trabalhavam em atividades remuneradas, comparar as percepções das respondentes sobre suas demandas parentais e envolvimento com o filho alvo em dias de carga de trabalho média e pesada, e verificar quais as associações entre estresse, burnout e envolvimento.

\section{MÉTODO}

\section{Participantes}

Participaram deste estudo 56 mães, predominantemente casadas (75\%), com média de 31,6 anos de idade $(d p=6,1)$, trabalhando em diversas profissões das áreas de serviços públicos e privados, indústria, comércio, saúde, educação, além de trabalhadoras autônomas. Em consonância com as diversas profissões das participantes, a renda familiar variou, concentrando-se principalmente na faixa de R $\$ 1000,00$ a R\$ 2000,00. Grande parte das mulheres $(80,3 \%)$ tinha um ou dois filhos, sendo que as idades das crianças alvo, fixadas entre 3 e 5 anos, estavam bem equilibradas: $32,1 \%$ eram crianças de 3 anos, $33,9 \%$ eram crianças de 4 anos, e 33,9\% eram crianças de 5 anos. Entre as crianças alvo que tinham irmãos $(51,7 \%)$, apenas quatro delas $(13,7 \%)$ eram primogênitas. Os irmãos variavam em idade de 6 meses a 21 anos.

\section{Locais de coleta de dados}

As respondentes foram contatadas em cinco escolas públicas de educação infantil que aceitaram participar do estudo após divulgação efetuada em parceria com a coordenadora de educação infantil do município onde a coleta foi efetuada, em uma cidade do interior de São Paulo que possuía, em média, 200.000 habitantes na época do estudo. Foram convidadas aproximadamente 140 mães no perfil desejado, as quais eram o público dominante nas escolas participantes, visto que atendiam prioritariamente filhos de mulheres que estavam trabalhando. Os convites foram realizados durante reuniões regulares entre pais e professores, e por meio de bilhetes às mães que não compareceram às reuniões. As mães que aceitaram participar informaram um número de telefone para contato e receberam uma ligação da pesquisadora, com o objetivo de planejar o melhor momento para a entrevista em suas residências.

\section{Instrumentos utilizados}

- Escala de Estresse (Cohen \& Williamson, 1988; versão traduzida por Sanjutá \& Barham, 2005), a fim de avaliar a frequência com a qual as participantes perceberam diferentes sintomas de estresse no mês anterior às entrevistas. A escala, tipo Likert, era graduada com pontuação de 1 a 10 , sendo que a pontuação mínima 1 correspondia a "nunca", 5 a " $50 \%$ do tempo" e 10 a " $100 \%$ do tempo". Esta escala foi utilizada em estudos anteriores focados no equilíbrio entre trabalho e família, conduzidos no Brasil, e as autoras encontraram índices de confiabilidade interna 
muito adequadas (Cia \& Barham, 2009; Vanalli \& Barham, 2008; Cia, D'Affonseca \& Barham, 2004).

- Escala de Cuidados e Envolvimento com o Filho, elaborada pelas autoras. Por meio deste instrumento, visou-se aferir o envolvimento das mães com seus filhos alvo, a partir da frequência de atividades cotidianas de cuidado e envolvimento, em dias de trabalho com carga média e pesada. A escala de pontuação possuía graduação entre 1 e 10 , correspondendo 1 a "muito inadequado", 5 a "nem adequado, nem inadequado", e 10 a "muito adequado" Também foi solicitado que as mães se avaliassem em relação ao desempenho das mesmas no papel materno, bem como a proximidade emocional e o envolvimento geral com seus filhos alvo. Deveria ser atribuída uma nota de satisfação que variava de um a dez nos itens propostos.

- Maslach Burnout Inventory - MBI - (BenevidesPereira, 2001) - Este instrumento é composto por 22 itens, pontuados em uma escala que varia de um a sete. Os itens abarcam as três dimensões da síndrome de burnout: exaustão emocional, despersonalização e reduzida realização profissional. Considera-se que altas pontuações nas dimensões exaustão e despersonalização, associadas a baixas pontuações na dimensão reduzida realização profissional, configuram níveis de burnout.

- Questionário de Variáveis Profissionais e Familiares, elaborado pelas autoras para captar o tempo despendido em diferentes responsabilidades das mães (tempo de serviço na profissão, horas e períodos de trabalho semanais, responsabilidade de cuidados com outros filhos e pessoas com dependência funcional, número de horas passadas interagindo ou não com os filhos alvo).

\section{Procedimentos}

O estudo foi aprovado pelo Comitê de Ética em Pesquisa da Universidade Federal de São Carlos (processo 0076.0.135.000-07). Quanto à coleta de dados, optou-se pela aplicação dos instrumentos em forma de entrevista, desde o piloto realizado. A entrevista envolvia o estabelecimento de rapport entre pesquisadora e respondente, aplicação das escalas e um período final que permitia que a respondente expressasse opiniões, sentimentos, reflexões e maiores informações relativas a questões de conflitos entre trabalho e família, durando, ao todo, cerca de uma hora.

Os dados foram tabulados e as análises estatísticas foram geradas a partir da utilização da ferramenta Statistical Package for Social Sciences. Em acordo com os objetivos do estudo, obteve-se medidas de tendência central e dispersão das respostas às escalas (médias e desvios padrões), cotejando as respostas aos itens referentes ao envolvimento materno em dias de carga média e pesada por meio de análises comparativas (teste- $t$, ANOVA e MANOVA) e analisou-se as relações entre estresse, burnout e envolvimento materno, por meio de correlações e regressões.

\section{RESULTADOS}

\section{Envolvimento Parental}

Os dados foram analisados segundo medidas estatísticas de tendência central e dispersão. A fim de comparar a frequência do envolvimento materno em dias de trabalho com carga média e pesada, foi utilizado o teste- $t$, e para verificar associações entre o estresse, o burnout e o envolvimento materno, utilizou-se o teste de correlação de Pearson.

As análises realizadas identificaram que em dias de carga de trabalho média, as mães responderam que se envolviam com alta frequência na grande maioria das atividades consideradas de envolvimento positivo (as médias variaram entre 7,1 e 9,9 de um máximo de 10 pontos). Apenas o item "Convidar outras crianças para brincar com seu filho em casa" teve média baixa $(M=5,7 ; d p=3,5)$. Os tipos de envolvimento mais frequentes nos dias de carga de trabalho média foram: "Perceber coisas novas que o filho aprende ou faz" $(M=9,9 ; d p=0,3)$, "Sorrir para o filho" $(M=9,9$; $d p=0,3)$, "Ajudar o filho em algo que ele peça" $(M=9,8 ; d p=0,6)$, "Acompanhar as tarefas escolares do filho" $(M=9,7 ; d p=0,9)$, "Dar carinho ao filho" $(M=9,7 ; d p=0,6)$; "Conversar com o filho" $(M=9,6$; $d p=0,8)$; "Perguntar para o filho sobre o seu dia na escola" $(M=9,5 ; d p=1,6)$.

Embora envolvendo uma interação que costuma ser negativa, a frequência com a qual as mães relatavam que puniam seus filhos também foi alta $(M=7,5, d p=3,0)$. Todavia, a frequência de outros envolvimentos negativos ("Perco o controle com o meu filho"; "Deixo de acompanhar alguma coisa que meu filho esteja fazendo por estar cansada demais") foi sempre baixa, menor do que cinco pontos. O item "Critico meu filho" teve pontuação maior que cinco $(M=6,3$; $d p=3,5$ ), porém nem sempre foi compreendido como negativo, já que segundo as mães, as críticas feitas muitas vezes eram construtivas, visando melhorias em comportamentos das crianças.

Nos dias de trabalho com carga pesada, muitos tipos de envolvimento tornaram-se significativamente menos frequentes. De forma geral, a frequência média do envolvimento das mães com seus filhos, em dias cuja carga de trabalho fora pesada, foi significativamente menor nos itens que abordam formas positivas de 
envolvimento, quando comparada a dias de carga de trabalho média. Os tipos de envolvimento mais afetados pela carga de trabalho da mãe foram: "Brincar com o filho" $(t(53)=7,472 ; p<0,001)$, "Relaxar estando com o filho" $(t(53)=6,180 ; p<0,001)$, "Dar carinho ao filho" $(t(53)=6,025 ; p<0,001)$, "Sorrir para o filho" $(t(53)=5,957 ; p<0,001)$, "Conversar com o filho" $(t(53)=5,723 ; p<0,001)$, "Contar histórias para o filho" $(t(53)=5,390 ; p<0,001)$. Em relação aos comportamentos negativos, pôde-se observar que a frequência de ocasiões quando as mães perdiam o controle com seu filho (envolvimento negativo) fora significativamente maior nos dias de carga pesada do que nos dias de carga de trabalho média $(t(53)=4,340$; $p<0,001)$.

Comparando-se as três avaliações globais de avaliação do envolvimento da mãe, a proximidade emocional foi o item que recebeu maior pontuação $(M=9,0 ; \quad d p=1,1)$, seguida pela avaliação do envolvimento geral $(M=8,8 ; d p=1,2)$. O desempenho das participantes enquanto mães recebeu a menor pontuação $(M=7,6 ; d p=1,2)$. Quando comparadas as três avaliações por meio do ANOVA, a proximidade emocional foi considerada significativamente mais alta do que a avaliação do desempenho das respondentes $(t(55)=6,427 ; p<0,001)$, e o envolvimento em geral das mães com os filhos obteve pontuações significativamente mais baixas do que o avaliação do desempenho das mães $(t(55)=5,721 ; p<0,001)$ e de sua proximidade emocional.

Considera-se bastante importante a alta pontuação da proximidade emocional e do envolvimento geral das mães com seus filhos, mesmo não havendo uma avaliação global do desempenho igualmente alta, o que pode ser resultado de falta de tempo em função de demandas no trabalho.

\section{Burnout}

$\mathrm{O}$ item com mais alta pontuação no MBI era associado à dimensão exaustão emocional, qual seja: "Eu me sinto cansada ao final da jornada de trabalho" $(M=5,1 ; d p=1,8)$. É possível inferir que as entrevistadas deixaram de se sentir realizadas com suas atividades profissionais atuais muito raramente (uma vez ao ano ou ao mês), embora ficassem exaustas tanto fisicamente quanto psicologicamente com certa frequência, visto que mais dois componentes da subescala exaustão emocional obtiveram pontuação média igual ou maior que quatro (com pontuações concentradas entre "algumas vezes ao mês", até "algumas vezes por semana"). São os itens: "Sinto-me esgotada emocionalmente devido ao meu trabalho" $(M=4,8 ; d p=1,9)$; e "Trabalhar com pessoas o dia todo me exige um grande esforço" $(M=4,0 ; d p=2,6)$.

A dimensão despersonalização sempre recebeu pontuações menores do que os itens relativos à exaustão emocional, apenas com exceção para a afirmativa "Não me preocupo realmente com o que ocorre às pessoas que atendo". Porém, cabe ressaltar que a amostra é constituída por mulheres de profissões diversas, portanto, nem sempre estas profissionais se deparariam com situações que gerassem real preocupação com seus clientes. A literatura acerca do burnout aponta ainda que os componentes desta dimensão geralmente recebem pontuações mais baixas porque estão associados a autoavaliações negativas, e provavelmente seja difícil para as pessoas admitir, declarar ou comentar a presença de tais posturas em seus relacionamentos de trabalho (Carlotto \& Câmara, 2004).

Usando uma análise para medidas repetidas (MANOVA), verificou-se que existia uma diferença significativa na pontuação das três dimensões - exaustão emocional, despersonalização e reduzida realização pessoal $(F(1,15)=14,573 ; p<0,001)$. A pontuação mais alta foi a de exaustão emocional, sendo que esta recebeu uma pontuação significativamente mais alta do que a de despersonalização $(t(15)=4,528 ; p<0,001)$ e do que reduzida realização profissional $(t(15)=4,466$; $p<0,001)$, apontando que a fadiga emocional percebida nas atividades profissionais das respondentes superava significativamente os sentimentos de reificação nas relações interpessoais do trabalho, bem como os sentimentos de falta de realização profissional.

\section{Estresse}

Houve variações grandes entre as respondentes nas pontuações dos itens desta escala (do valor mínimo possível até o valor máximo possível). Em função disso, outro indicador da variação nas respostas, o desvio padrão, também foi relativamente alto para todos os itens. Assim, nesta amostra houve respondentes pouco estressados e outras altamente estressadas. Considerando as pontuações médias, pôde-se observar que, no mês anterior à entrevista, as respondentes lidaram com muitos dos sintomas de estresse com alta frequência, atribuindo médias que se concentraram principalmente entre cinco e sete pontos (isto é, sentindo sintomas de estresse entre 50 e $70 \%$ do tempo).

As respondentes indicaram médias superiores a cinco pontos para itens relativos à ansiedade, ao cansaço e à sobrecarga de atividades. Exemplos relacionados à ansiedade são os itens "Senti-me ansiosa ou preocupada" $(M=7,1 ; d p=2,5)$, "Não me senti relaxada" 
$(M=6,3 ; d p=2,6)$, "Não me senti de bem com a vida" e "Tive dificuldades para me concentrar" (ambos com $M=5,1 ; d p=3,3)$. O cansaço foi representado pelos itens "Não me senti cheia de energia" $(M=6,0 ; d p=2,8)$ e "Senti-me cansada, esgotada" $(M=5,7 ; d p=2,9)$. A sobrecarga de atividades foi refletida pelas sentenças "Não me senti capaz de lidar com o estresse" $(M=5,6$; $d p=3,3)$, "Senti-me sufocada pelas coisas" $(M=5,2$; $d p=2,9)$, e "Senti-me incapaz de dar conta de tudo" $(M=5,1 ; d p=3,1)$. Porém, a frequência de sintomas ligados a problemas de saúde mental mais graves (depressão, raiva prolongada e problemas de saúde psicossomáticos) foram apontados como ocorrendo com menor frequência, com médias sempre inferiores a cinco pontos. Desta forma, é possível inferir que a maior parte das entrevistadas sofreram com muitos sintomas de estresse no mês anterior à entrevista, mas sem chegar a níveis intoleráveis do mesmo.

\section{Associações entre as variáveis}

Pode-se observar na Tabela 1 as correlações obtidas entre as variáveis burnout, estresse e envolvimento parental. A dimensão do MBI denominada Exaustão Emocional foi a que mais apresentou correlações entre as variáveis de interesse, correlacionando-se negativamente com o envolvimento materno em forma da avaliação do vínculo emocional entre mãe e filho, da avaliação geral de relacionamento entre mãe e filho e das horas despendidas com o filho alvo nos dias em que as mães trabalhavam. Este último item foi o único que obteve correlação significativa também com a dimensão Despersonalização. A dimensão Reduzida Realização Pessoal associou-se de forma significativa e negativa somente com a avaliação do vínculo emocional materno. Os escores totais do MBI apresentaram correlações negativas e significativas com as variáveis: Avaliação geral de relacionamento entre mãe e filho, Horas despendidas com filho alvo em dias de trabalho e Horas interagindo com filho alvo em dias de trabalho.

De forma geral, quanto mais altas eram as pontuações do burnout, mais baixas foram as pontuações dos indicadores de envolvimento parental. Isto é, as respondentes com graus maiores de estresse e burnout estavam menos envolvidas emocionalmente e de forma geral com seus filhos, tanto em número de horas diárias passadas em companhia ou interação com a criança quanto em atividades de cuidado e educação infantil.

\section{DISCUSSÃO}

Os resultados apoiaram a hipótese de que mães que passam mais tempo trabalhando sentiam-se mais afastadas dos seus filhos e mais estressadas, contribuindo para a melhor compreensão deste momento na vida de mulheres que trabalham e de seus filhos pequenos.

Pesquisadores (Barham \& Vanalli, 2012; Soares, Teixeira, Loreto, \& Pereira, 2011; Cooper \& Lewis, 2000) discutem que a sobrecarga em trabalhadores com dupla jornada de trabalho é frequentemente fruto de ativas demandas no ambiente de trabalho e também no lar. Não somente o número de horas trabalhadas pode ser desgastante, mas também há incompatibilidade de horários entre os parceiros e entre a família e suas necessidades. Dentro de nossa cultura, considerase que os pais, e especialmente as mães, precisam acompanhar o que acontece com seus filhos pequenos e estar presente no cotidiano deles. Embora trabalhar fora seja possível, importante e necessário, dispor de tempo adequado para se envolver com seus filhos, diariamente, também é essencial. Assim, nesta fase da

TABELA 1

Correlações entre Medidas de Burnout, Estresse e Medidas de Envolvimento Materno

\begin{tabular}{|c|c|c|c|c|c|}
\hline \multirow[b]{2}{*}{ Burnout ou Estresse } & \multicolumn{4}{|c|}{ Envolvimento Materno } & \multirow[b]{2}{*}{ Total } \\
\hline & $\begin{array}{c}\text { Em dias de } \\
\text { carga pesada }\end{array}$ & $\begin{array}{l}\text { Tempo total } \\
\text { com filho }\end{array}$ & $\begin{array}{l}\text { Tempo em } \\
\text { interação } \\
\text { com filho }\end{array}$ & Emocional & \\
\hline 1. Burnout-Exaustão Emocional & - & $-0,405^{b}$ & - & $-0,427^{b}$ & $-0,415^{b}$ \\
\hline 2. Burnout-Despersonalização & - & - & - & - & $-0,447^{c}$ \\
\hline 3. Burnout - Reduzida Realização profissional & - & - & - & $-0,436^{b}$ & - \\
\hline 4. Burnout - Total & - & $-0,420^{b}$ & $-0,291^{a}$ & - & $-0,419^{b}$ \\
\hline 5. Estresse & $-0,287$ a & $-0,336^{a}$ & - & $-0,301$ a & - \\
\hline
\end{tabular}

${ }^{\mathrm{a}} \mathrm{p}<0,05 ;{ }^{\mathrm{b}} \mathrm{p}<0,01 ;{ }^{\mathrm{c}} \mathrm{p}<0,001$. 
vida familiar, demandas profissionais que dificultam um bom desempenho diário no papel parental têm um impacto direto no bem-estar das mães, que por vezes acabam precisando priorizar uma das duas funções em detrimento da outra (Soares, Teixeira, Loreto \& Pereira, 2011).

De acordo com Lim e Kim (2014), horários inflexíveis e horas extras podem ser bastante inconvenientes à medida que impossibilitam o atendimento de necessidades familiares, como por exemplo, ir à uma reunião de pais ou levar o filho ao dentista. Portanto, parece necessário que as políticas relacionadas a trabalhadores com filhos pequenos (ou cuidando de outros familiares com alto nível de dependência funcional) sejam revistas e ampliadas, considerando, por exemplo, as possibilidades de horas de trabalho mais flexíveis e a criação de diferentes categorias de licenças que melhor garantam a disponibilidade de tempo para assumir alguns cuidados para com filhos pequenos, que deveriam ser realizados pelos pais (por exemplo, quota de ausências para cobrir horários perdidos no trabalho, ou para cuidar de um filho doente). Seria importante tentar promover o uso destas opções por ambos os membros do casal, para equilibrar os impactos sobre a carreira de ambos e para promover o envolvimento paterno. Parece indispensável também que o incentivo ao uso desses benefícios seja transmitido ao trabalhador de forma que ele realmente o perceba como um direito, evitando preocupações com consequências negativas em seu trabalho (Goulart Jr., Feijó, Cunha, Correa, \& Gouveia, 2013).

Diante do exposto, cabe retomar as discussões iniciais do texto acerca dos possíveis efeitos do trabalho dos pais, enquanto parte do exossistema das crianças (segundo a abordagem bioecológica de Bronfenbrenner, 1979/1996) no desenvolvimento infantil. Neste estudo, avaliamos as relações entre o estresse experimentado por pais no seu trabalho profissional e a qualidade e extensão do envolvimento parental que, por sua vez, influencia no desenvolvimento infantil. Os resultados do presente estudo mostram que a qualidade do envolvimento das participantes variou em função de estresse ligado ao trabalho. Portanto, acredita-se que seja importante que os pais tenham melhores condições para manter a constância do seu envolvimento parental, não apenas nos cuidados básicos, mas também em uma educação baseada em trocas constituídas por afeto, envolvimento e interesse pelo filho, pois esta conduta é provavelmente tão importante quanto a manutenção dos cuidados físicos direcionados às crianças pequenas. Comportamentos como ouvir o filho, reconfortá-lo, interagir com ele brincando, lendo e fazendo refeições, em muito contribuem para o desenvolvimento adequado de aspectos como a auto-estima das crianças. De maneira semelhante àquela que ocorre ao longo do tempo, quando cuidados com a alimentação e higiene são inadequadamente desempenhados, um envolvimento parental que negligencia as necessidades de afeto com certa frequência pode conduzir a danos até mesmo severos ao desenvolvimento infantil (Simões, Farate, \& Pocinho, 2011).

O bem-estar das mães também reflete a maneira como elas avaliam suas situações e seus desempenhos, no trabalho e na esfera familiar. Empregadores que criam um ambiente mais apoiador para funcionários com filhos pequenos, junto com padrões culturais que conduzam as pessoas a desenvolverem expectativas realistas em relação ao seu desempenho familiar, podem auxiliar na redução do estresse percebido, evitando que o mesmo se cronifique, a fim de evitar situações de exaustão (burnout) e de pior qualidade nas interações com seus filhos. A discussão de Lim e Kim (2014) sobre os conflitos entre trabalho e família e seus efeitos destacam o potencial de influência destes conflitos nas crianças, favorecendo o desenvolvimento de percepções mais negativas sobre o papel do trabalho na vida desses futuros trabalhadores.

Não se pode negar que uma parcela dos homens contribua de maneira mais significativa do que no passado na educação dos filhos e no serviço doméstico, porém essa participação ainda é incipiente, ficando bastante claro que embora haja colaboração masculina, a responsabilidade pelo âmbito doméstico ainda é socialmente imputada às mulheres (Barham \& Vanalli 2012). Também não é possível ignorar que as mulheres têm conquistado seu espaço no mundo do trabalho, mas isso não deve significar o abandono da maternidade quando ela é desejada. No entanto, é necessário que as políticas trabalhistas continuem sendo revistas e evoluam a fim de incentivar uma maior participação de uma parcela maior dos homens na vida de seus filhos, visto que a solução para a sobrecarga enfrentada por muitas mulheres não será alcançada simplesmente dividindo de forma mais igual as responsabilidades domésticas entre os membros do casal, até porque esta solução é indisponível para as famílias monoparentais e famílias que dependem da renda de um pai cujo trabalho dificulta seu envolvimento em rotinas familiares. Faz-se importante garantir aos trabalhadores benefícios que auxiliem na conciliação entre trabalho e família (Lim \& Kim, 2014), principalmente enquanto as crianças são pequenas ou apresentam dependência prolongada em função de deficiências. Sem dúvida, alternativas apropriadas também precisam ser criadas para trabalhadores dando assistência a parentes idosos e enfermos, a exemplo de países que já adotaram 
diversas políticas de bem estar social (Lero, Spinks, Fast, Hilbrecht, \& Tremblay, 2012).

Além da necessidade da ampliação da rede de apoio aos indivíduos, é preciso cuidar daquilo que já existe. Os direitos conquistados, como aqueles previstos pelo Estatuto da Criança e do Adolescente e pela Consolidação de Leis Trabalhistas, precisam de uma revisão que conduza ao cumprimento dessas prerrogativas, tendo em vista o favorecimento das crianças e seus genitores. Considerando que as respondentes deste estudo foram encontradas em escolas públicas de educação infantil, cabe salientar que leis e ações trabalhistas e sociais que possam fortalecer a rede de apoio de pais e mães com filhos na primeira infância são ainda incipientes, considerando a já citada carência de políticas públicas para pessoas nesta etapa da vida. Diante da proposta desse serviço como "direito da criança, opção da família e dever do Estado" (Brasil, 2006, p. 5), definitivamente, quando as mães e pais trabalham fora, cuidados infantis de meio-período não suprem adequadamente as necessidades de cuidado e educação das crianças em seus primeiros anos, e esta é uma realidade em todas as regiões do país. Ademais, sob uma perspectiva sistêmica, essas mudanças contribuiriam para a reconfiguração das estruturas políticas e culturais nacionais, denominado por Bronfenbrenner (1979/1996) como o macrossistema, possibilitando reformulações no cenário de desenvolvimento da infância brasileira.

Também é possível buscar formas de aliviar os pais de algumas tarefas domésticas que poderiam ser terceirizadas. Assim, é importante atentar para a possibilidade de implementação de serviços de apoio para com o trabalho doméstico, subsidiados pelo governo, para reduzir a carga de trabalho no interior destas famílias (Araújo, Pinho, \& Almeida, 2005). As organizações também devem estar atentas às suas políticas de gestão, a fim de que os problemas de saúde do trabalhador possam ser minimizados, evitando-se o adoecimento e a consequente perda de talentos (Oliveira, Cavazotte, \& Paciello, 2013). Diante disso, Goulart Jr., Feijó, Cunha, Correa e Gouveia (2013), bem como Oliveira, Cavazotte e Paciello (2013), chamam a atenção para a urgente mudança de cultura das organizações para o reconhecimento da interdependência das relações entre trabalho e família e seus efeitos na vida do trabalhador. Além dos benefícios diretos a mães, pais e crianças, a revisão de políticas e a criação de uma rede de apoio se fazem importantes por possibilitar auxílios na administração das "duas carreiras", uma vez que a ausência dos mesmos parece prejudicar as possibilidades de equilíbrio entre trabalho e família, favorecendo também problemas profissionais, além dos familiares (Soares, Teixeira, Loreto, \& Pereira, 2011).

Algumas limitações dos resultados aqui sintetizados são: o baixo número de participantes na pesquisa e a utilização de um único meio de avaliação (autorrelato). A dificuldade encontrada para recrutar participantes confirma a pressão de tempo enfrentada por mulheres que também trabalham fora e cuidam de seus filhos pequenos. Porém, aparentemente tais limitações não têm impedido a captação de informações referentes às percepções de mães que trabalham sobre a conciliação entre trabalho e família e o relacionamento que as mesmas têm mantido com seus filhos na segunda infância dos mesmos.

Sugere-se a continuidade da execução de estudos desta ordem, com variados delineamentos, e o desenvolvimento de instrumentos para avaliar o "burnout familiar" e verificar a relação oposta, entre estresse familiar e envolvimento profissional. Com a obtenção de informações sobre as possibilidades e limites inerentes aos esforços de conciliar responsabilidades profissionais e familiares, espera-se que seja possível identificar iniciativas que podem melhorar nossa capacidade de equilibrar estes envolvimentos, em diferentes fases da vida profissional e familiar.

\section{REFERÊNCIAS}

Araújo T. M., Pinho, P. S., \& Almeida, M. M. G. (2005). Prevalência de transtornos mentais comuns em mulheres e sua relação com as características sociodemográficas e o trabalho doméstico. Revista Brasileira de Saúde Materna e Infantil, 5(3), 337-348. http://dx.doi.org/10.1590/S1519-38292005000300010

Barham, E. J. \& Vanalli, A. C. G. (2012). Trabalho e família: perspectivas teóricas e desafios atuais. Revista Brasileira de Psicologia Organizacional e do Trabalho, 12(1), 47-59.

Benevides-Pereira, A. M. T. (2001). Maslach Burnout Inventory e suas adaptações para o Brasil. Anais da XXXII Reunião Anual de Psicologia. Rio de Janeiro, RJ, 84-85.

Benevides-Pereira, A. M. T. (2010). Burnout: Quando o Trabalho Ameaça o Bem-estar do Trabalhador. São Paulo: Casa do Psicólogo. 
Brasil. (1990). Estatuto da Criança e do Adolescente. Lei Federal n 8069 de 13 de julho de 1990. Recuperado em: 13 set. 2013, disponível em: <http://www.planalto.gov.br/ccivil_03/Leis/L8069.htm>.

Brasil (2001). Decreto-Lei no 5.452 - Aprova a Consolidação das Leis do Trabalho. Recuperado em: 26 maio 2015. disponível em: <http://www.planalto.gov.br/ccivil_03/decreto-lei/del5452compilado.htm>.

Brasil (2006). Politica Nacional de Educação Infantil: Pelo Direito das Crianças de 0 a 6 Anos à Educação. Brasília: $\mathrm{MEC} / \mathrm{SEB}$.

Brasil. (2012). Ministério do Planejamento, Orçamento e Gestão. Instituto Brasileiro de Geografia e Estatística. Síntese de Indicadores- Pesquisa Nacional por Amostra de Domicílios - 2011. Rio de Janeiro, RJ.

Bronfenbrenner, U. (1996) Ecologia do Desenvolvimento Humano: Experimentos Naturais e Planejados. Porto Alegre: Artes Médicas. (Original publicado em 1979).

Cia, F. \& Barham, E. J. (2008). Trabalho noturno e o novo papel paterno: Uma interface difícil. Estudos de Psicologia (Campinas), 25, 211-221. http://dx.doi.org/10.1590/S0103-166X2008000200006

Cia, F. \& Barham, E. J. (2009). O envolvimento paterno e o desenvolvimento social de crianças iniciando as atividades escolares. Psicologia em Estudo, 14, 67-74. http://dx.doi.org/10.1590/S1413-73722009000100009

Cia, F., D’Affonseca, S. M., \& Barham, E. J. (2004). A relação entre o envolvimento paterno e o desempenho acadêmico dos filhos. Paidéia: Cadernos de Psicologia e Educação, 14 (29), 277-286.

Cia, F. \& Barham, E. J. (2005). A relação entre o turno de trabalho do pai e o autoconceito do filho. Revista Psico, 36(1), 29-35.

Cia, F., Barham, E. J., \& Fontaine, A. M. G. V. (2012). Desempenho acadêmico e autoconceito de escolares: contribuições do envolvimento paterno. Revista Estudos de Psicologia, 29(4), 461-470. http://dx.doi.org/10.1590/S0103166X2012000400001

Cooper, C. L. \& Lewis, S. (2000). E Agora, Trabalho ou Família? Pais e Mães que Trabalham Fora Aprendem como Enfrentar as Sobrecargas Profissionais e Familiares do Dia-a-dia. São Paulo: Editora Tâmisa.

Dekovic, M. \& Meuis, W. (1997). Peer relations in adolescence: Effects of parenting on adolescents' self-concept. Journal of Adolescence, 97, 1163-1176. http://dx.doi.org/10.1006/jado.1996.0074

Dessen, M. A. \& Braz, M. P. (2005). A família e suas inter-relações com o desenvolvimento humano. In M. A. Dessen \& A. L. Costa Júnior (Orgs.). A Ciência do Desenvolvimento Humano: Tendências Atuais e Perspectivas Futuras (pp. 132-151). Porto Alegre: Artmed.

Eisenstein, E. \& Souza, R. P. (1993). Situações de Risco à Saúde de Crianças e Adolescentes. Petrópolis: Vozes.

Ferreira, S. H. A. \& Barreira, S. D. (2010). Ambiente familiar e a aprendizagem escolar em alunos da educação infantil. Psico (Porto Alegre), 41(4), 462-472.

Goulart Jr., E., Feijó, M. R., Cunha, E. V., Correa, B. J., \& Gouveia, P. A. E. S. (2013). Exigências familiares e do trabalho: Um equilíbrio necessário para a saúde de trabalhadores e organizações. Pensando Famílias, 17(1), 110-122.

Lero, D., Spinks, N., Fast, J., Hilbrecht, M., \& Tremblay, D.G. (2012). Availability, accessibility and effectiveness of workplace supports for Canadian caregivers. Guelph ON: Centre for Families, Work \& Well-being, University of Guelph.

Lim, V. K. G \& Kim, T. Y. (2014). The Long Arm of the Job: Parents' Work-Family Conflict and Youths' Work Centrality. Applied Psychology Special Section - International Perspectives on Work and Family, 63(1), 96-129. http://dx.doi.org/10.1111/j.1464-0597.2012.00527.x

Mondin, E. M. C. (2008). Práticas educativas parentais e seus efeitos na educação dos filhos. Psicologia Argumento, 26(54), 233-244.

Nunes-Costa, R. A.; Lamela, D. J. P. V., \& Figueiredo, B. F. C. (2009). Adaptação psicossocial e saúde física em crianças de pais separados. Jornal de Pediatria, 85(5), 385-396, http://dx.doi.org/10.1590/S0021-75572009000500004

Oliveira, L. B., Cavazotte, F. S. C. N, \& Paciello, R. R. (2013). Antecedentes e consequências dos conflitos entre trabalho e família. Revista de Administração Contemporânea, 17(4), 418-437, http://dx.doi.org/10.1590/S141565552013000400003

Patias, N.D, Siqueira, A. C., \& Dias, A. C. G. (2013). Práticas educativas e intervenção com pais: A educação como proteção ao desenvolvimento dos filhos. Mudanças - Psicologia da Saúde, 21(1), 29-40. http://dx.doi.org/10.15603/2176-1019

Pedroso, M. L. R. \& Motta, M. G. C. (2010). Cotidianos de famílias de crianças convivendo com doenças crônicas: microssistemas em intersecção com vulnerabilidades individuais. Revista Gaúcha de Enfermagem, 31(4), 633-639. http://dx.doi.org/10.1590/S1983-14472010000400004

Pinquart, M. \& Silbereisen, R. K. (2005). Influences of parents and siblings on the development of children and adolescents. In V. L. Bengston, A. C. Acock, K. R. Allen, P. Dilworth-Anderson, \& D. M. Klein (Org.). Sourcebook of Family Theory \& Research, (pp. 367-391). Thousand Oaks, CA: Sage.

Sanjutá, G. \& Barham, E. J. (2005). Uma análise do equilíbrio trabalho e família no contexto brasileiro. Revista Nucleus, 3(1), 33-38.

Simões, S., Farate, C., \& Pocinho, M. (2011). Estilos educativos parentais e comportamentos de vinculação de crianças em idade escolar. Interações (Coimbra), 20, 75-99. 
Soares, C. \& Sabóia, A. L. (2007). Tempo, Trabalho e Afazeres Domésticos: Um Estudo com Base nos Dados da Pesquisa Nacional por Amostra de Domicílios de 2001 a 2005. Rio de Janeiro: IBGE.

Soares, L. M., Teixeira, K. M. D., Loreto, M. D. S., \& Pereira, E. T. (2011). Maternidade e trabalho: percepção de bancárias. Oikos: Revista Brasileira de Economia Doméstica, 22(1), 210-229.

Vanalli, A. C. G. (2012). Conciliação entre profissão, conjugalidade e paternidade para homens e mulheres com filhos na primeira infância. Tese de Doutorado, Programa de Pós-Graduação em Psicologia, Universidade Federal de São Carlos. São Carlos: UFSCar.

Vanalli, A. C. G. \& Barham, E. J. (2008). A demanda para políticas públicas adicionais para trabalhadores com filhos pequenos: o caso de professoras. Temas em Psicologia, 16(2), 231-241.

Zanfelici, T. O. (2009). Fatores de risco ao envolvimento materno com filhos pré-escolares. Dissertação de Mestrado, Programa de Pós-Graduação em Educação Especial, Universidade Federal de São Carlos. São Carlos: UFSCar.

Autores:

TATIANE OliveIRA ZANFELICI - Doutora, Centro Universitário Hermínio Ometto.

EliZABETH JOAN BARHAM - Doutora, Universidade Federal de São Carlos.

Endereço para correspondência:

Tatiane Oliveira Zanfelici

Rua Sebastião Camargo Schimidt, 70, ap. 22 - Edifício Tangará

CEP 13607-191 Araras, SP, Brasil

Recebido em: 22.09 .14

Aceito em: 17.06.15 